\title{
Correlation of blood $\mathrm{Na}^{+}$and $\mathrm{K}^{+}$levels with Body Mass Index in population of Garhwal region of Uttarakhand
}

\author{
Vijay Pandey ${ }^{1}$, Hemant Kumar Dutt ${ }^{2 *}$, Ganesh Singh ${ }^{3}$, Amritha P. Vinod ${ }^{4}$ \\ ${ }^{1}$ Veer Chandra Singh Garhwali Government Medical Sciences and Research Institute, Srinagar, Uttarakhand, India. ${ }^{2}$ Department of Pharmacology, Kannur \\ Medical College, Anjarakandy, Kannur, Kerala, India. ${ }^{3}$ Department of Community Medicine, Lala Lajpat Rai Memorial Medical College and S.V.B.P. \\ Hospital, Meerut, India. ${ }^{4}$ Department of Pharmacology, Kannur Medical College, Anjarakandy, Kannur, Kerala, India.
}

\begin{tabular}{|c|c|}
\hline ARTICLE INFO & ABSTRACT \\
\hline $\begin{array}{l}\text { Article history: } \\
\text { Received on: } 03 / 06 / 2016 \\
\text { Revised on: } 07 / 07 / 2016 \\
\text { Accepted on: } 25 / 08 / 2016 \\
\text { Available online: } 31 / 01 / 2017\end{array}$ & $\begin{array}{l}\text { Higher blood electrolyte } \mathrm{Na}^{+} \text {and } \mathrm{K}^{+} \text {levels and disturbance in Body Mass Index (BMI), both are associated with } \\
\text { risks of various health complications such as hypertension, coronary artery diseases, type } 2 \text { diabetes, } \\
\text { hyperlipidemia and mortality. This study was conducted to find out any correlation between the blood level of } \\
\text { these electrolytes and BMI so that better adjustment of these parameters can reduce the morbidity as well as } \\
\text { mortality of these serious health complications. } 204 \text { healthy volunteers participated in the study. History }\end{array}$ \\
\hline $\begin{array}{l}\text { Key words: } \\
\text { BMI, Blood Pressure, } \\
\text { Electrolyte, Obesity, } \\
\text { Potassium, Sodium. }\end{array}$ & $\begin{array}{l}\text { regarding diet and lite style was noted in the form of questionnaire. Height and weight of the patient and blood } \\
\text { pressure was recorded. Blood was collected in a sterile vial for blood } \mathrm{Na}^{+} \text {and } \mathrm{K}^{+} \text {levels. Data analysis showed a } \\
\text { negative correlation of } \mathrm{Na}^{+} \text {and } \mathrm{K}^{+} \text {levels with BMI. The study showed a significant positive correlation of BMI } \\
\text { with blood pressure. It was also found that } \mathrm{Na} \text {. has positive correlation and } \mathrm{K}+\text { has negative correlation with } \\
\text { systolic blood pressure. The study concludes that there is a strong association of BMI with blood } \mathrm{Na}^{+} \text {and } \mathrm{K}^{+} \\
\text {levels and blood pressure. We need to spread awareness about BMI and electrolytes imbalance in the } \\
\text { community to prevent the related complications. }\end{array}$ \\
\hline
\end{tabular}

\section{INTRODUCTION}

High Body Mass Index (BMI) and disturbance in body Sodium $\left(\mathrm{Na}^{+}\right)$and Potassium $\left(\mathrm{K}^{+}\right)$levels are associated with high risk of adverse health effects. Obesity has been associated with an increased risk of coronary artery diseases, diabetes mellitus type 2, hyperlipidemia, hypertension and mortality. A metaanalysis observed an risk of about $10 \%$ in risk of coronary artery diseases with each 5 unit increase in BMI (Bogers et al., 2007). Hypertension is a major risk factor for CVD. It has been estimated that shift in the population blood pressure (BP) distribution to a $5 \mathrm{~mm} \mathrm{Hg}$ lower level may prevent $1 / 3$ of strokes and 1/6 of coronary events (MacMohan et al., 1990). $\mathrm{Na}^{+}$and $\mathrm{K}^{+}$ have been implicated in aetiology of hypertension. A high potassium diet has been claimed to give protection on high

* Corresponding Author

Hemant Kumar Dutt, Associate Professor, Department of Pharmacology, Kannur Medical College, Anjarakandy, Kannur, Kerala, India.

E-mail:dr.hemantkdutt@yahoo.co.in sodium diet, but in most population studies no such association has been found (Warren and Aberg, 1979). Meta analysis of randomised trial found BP falls of 3-5 mm $\mathrm{Hg}$ systolic and 1-2 mm $\mathrm{Hg}$ diastolic for $\mathrm{Na}^{+}$reduction in hypertensive's and reduction half this size in normotensives (He and MacGregor, 2002). For $\mathrm{K}^{+}$ supplementation BP decreases of more than $3 \mathrm{~mm} \mathrm{Hg}$ systolic and $2 \mathrm{~mm} \mathrm{Hg}$ diastolic have been reported (Burgess et al., 1999). Intervention studies of effects of weight loss, low $\mathrm{Na}^{+}$intake and $\mathrm{K}^{+}$supplementation on BP have been inconsistent as to whether weight loss leads to lower BP with or without $\mathrm{Na}^{+}$intake (Dahil et al., 1958) and in at least one study with or without increased $\mathrm{K}^{+}$ intake (Heyden et al., 1972).

It is unclear whether lower $\mathrm{Na}^{+}$intake decreases BP equally in overweight and non overweight individuals (Cooper $e t$ al., 1984), also combined effect of weight and $\mathrm{Na}^{+}$reduction on BP have not yet been quantified (Prineas, 1991). High sodium intake and unawareness about BMI as a factor for various adverse health complication needs assessment, so that lifestyle changes can be advised to the community. 
This will ensure a reduction in morbidity and mortality due to these complications. So, the present study is undertaken to analyse the correlation between these factors.

There has been no known research related to blood $\mathrm{Na}^{+}$ and $\mathrm{K}^{+}$levels and its correlation with BMI is conducted in Garhwal region. Considering the unbalanced dietary habits of people and change in their life style, there is a need to address these problems at primordial stage by giving information about good dietary habits and better life style for healthy living.

Effects of age, BMI and electrolytes $\left(\mathrm{Na}^{+}\right.$and $\left.\mathrm{K}^{+}\right)$as risk factor for hypertension have been extensively studied before. However, the relationship between these parameters, within their physiological range and blood pressure remained mostly uncovered. Previous researches repeatedly demonstrated elevation of blood pressure with age in those above 40 year old (Smulyan et al., 1983), most likely due to vascular changes. Additional studies have proved the positive correlation between age and blood pressure among those less than 20 years (Gundogdu, 2008, Dores et al., 2010). Similarly the association between BMI and Blood Pressure was extensively investigated in children (Falkner et al., 2006, Gundogdu, 2008), nonetheless, comparable studies in middle age adults are very limited (Saely et al., 2009, Dores et al., 2010).

This study helps to evaluate the association of blood $\mathrm{Na}^{+}$, $\mathrm{K}^{+}$levels and $\mathrm{Na}^{+}-\mathrm{K}^{+}$ratio with BP by quantifying effects of adjustment for BMI and by exploring possible interactions of these variables with $\mathrm{BMI}$ in relation to adverse health complications.

\section{MATERIALS AND METHODS}

This cross sectional study was conducted by the Department of Pharmacology, Veer Chandra Singh Garhwali Government Medical Science and Research Institute at HNB Base Teaching Hospital, Srikot, Srinagar, Pauri Garhwal, Uttarakhand between 15 July 2014 to 15 September 2014 as part of Short Term Studentship Project 2014 approved and sponsored by Indian Council Of Medical Research, New Delhi (Reference ID: 2014 02746).

Participants were provided written or verbal (if not literate) informed consent after the approval of all study procedures by institutional Ethics Committee (Review Letter No. IEC/VCSGGMSRI/27/2014 dated 08/7/2014). All procedures were conducted in accordance with institutional ethical guidelines.

\section{Inclusion criteria}

All the normotensive and non diabetic individuals of either gender between the age of 18 to 65years who came to the OPD of Base hospital, Srinagar, Garhwal and volunteered to participate were included during the period of study.

\section{Exclusion criteria}

Patients in the age <18years or >65years, pregnant subjects, patients with diabetes, hyperlipidaemia, subjects on any medication therapy, any congenital or acquired condition which affects $\mathrm{Na}^{+}$and $\mathrm{K}^{+}$blood levels and BMI will be excluded from the study.

\section{Methods of Data Collection}

After obtaining the informed consent, person's biological data viz. age, sex, weight, height and blood pressure were recorded.

\section{Anthropometric Parameters Height}

The subject is asked to stand on a horizontal plane with heals together, stretching upwards to the fullest extent and hands loosely handling down. The marked Frankfurt plane is made horizontal. The anthropometer is kept vertical with left hand of the investigator and the horizontal sliding arm is made to touch vertex of the subject. The reading was noted at horizontal arm on anthropometer from the level on which subject was standing (Dudekula et al., 2012).

\section{Weight}

To measure subject's weight, standard portable weighing machine was used. The subject was asked to stand erect with minimum clothing and barefoot on weighing machine and the weight was noted (Dudekula et al., 2012).

\section{BMI (BMI)}

The BMI was calculated by Weight in Kilogram $(\mathrm{Kg})$ and Height in meter $(\mathrm{m})$ using a formula: $\mathrm{BMI}=\mathrm{Kg} / \mathrm{m}^{2}$

BMI categories were made as per BMI range (Patil et al., 2012): Underweight (BMI < 18.5), Normal (BMI 18.5 - 22.99), Overweight (BMI $23-24.99)$ and Obese (BMI $>25)$

\section{Blood Pressure Measurement}

Subjects were seated in a chair with their back supported and their arms rested at heart level. Measurement was performed with the subject not having ingested coffee or smoked for 30 minutes and after at least five minutes of rest. The first Korotkoff sound for Systolic Blood Pressure (SBP) and fifth Korotkoff sound for Diastolic Blood Pressure (DBP) were recorded by the height of mercury column on sphygmomanometer and the two readings were taken and averaged (Syed and Qureshi, 2012). Mean Arterial Pressure (MAP) was calculated by the formula: MAP $=[(2 \times$ $\mathrm{DBP})+\mathrm{SBP}] \div 3$.

\section{Biochemical Analysis}

Venous blood samples were drawn, centrifuged and analyzed (by commercially available kits) for estimation of electrolytes $\left(\mathrm{Na}^{+}\right.$and $\left.\mathrm{K}^{+}\right)$. The analysis of serum electrolytes was carried out in auto-analyzer for $\mathrm{Na}^{+}$and $\mathrm{K}^{+}$using ion selective electrode measurement (Jankunas, 2002).

The data was tabulated to make it easy to understand and use for further purpose. 


\section{Data collection procedure}

Data was collected in the form of case examination record sheet which would be preserved for any future use. All data would be kept confidential and no citing of any individual's identity would be done at any point of time during research or thereafter.

\section{Statistic Analysis}

Statistical differences between the BMI and other parameters viz. $\mathrm{Na}^{+}, \mathrm{K}^{+}, \mathrm{Na}^{+} / \mathrm{K}^{+}$ratio, SBP DBP and MAP were tested by one way analysis of variance (ANOVA) followed by post hoc multiple comparisons and Pearson's correlation. $\mathrm{P}$ values were calculated referring to the appropriate tables. Values of $\mathrm{P}<0.05$ were considered as statistically significant.

\section{OBSERVATIONS \& RESULTS}

A total of 204 healthy volunteer were studied who came to the OPD and willingly choose to take part in the study. The information regarding the distribution pattern of participants as per gender, diet and life style is provided in Figure 1 and number of participants under each BMI category is shown in Figure 2.

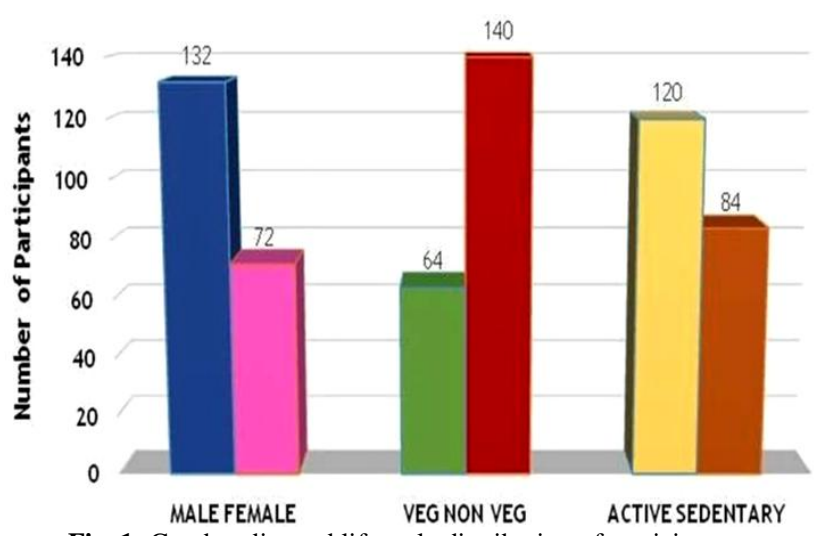

Fig. 1: Gender, diet and life style distribution of participants.

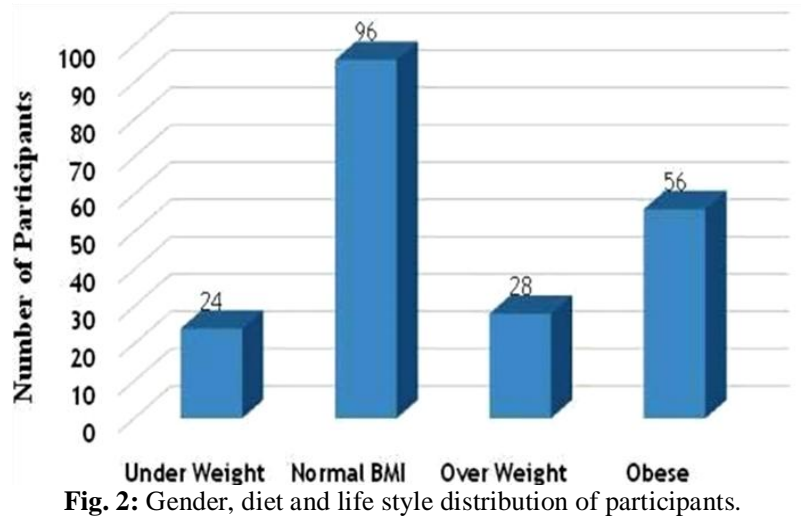

Analysis by Pearson's correlation coefficient, a negative correlation of BMI with serum $\mathrm{Na}+$ levels \& $\mathrm{K}^{+}$levels was seen which was statistically significant $(\mathrm{p}<0.05)$. Comparing with each other, BMI showed a more negative correlation with $\mathrm{Na}^{+}$level than $\mathrm{K}^{+}$level. On analysis with ANOVA, the effect of BMI on SBP, DBP and MAP was found to be statistically significant $(p<0.05)$. When comparing the Obese BMI category with the Normal with reference to Systolic Blood Pressure and done by post hoc multiple comparison test, it was found to be statistically significant $\quad(\mathrm{p}<0.05)$. Similarly on Pearson's correlation coefficient, the serum $\mathrm{Na}^{+}$is shown to be more positively related to SBP and the serum $\mathrm{K}^{+}$to be negatively related to SBP which was found to be statistically significant $(\mathrm{p}<0.05)$. No statistical significance was found when comparing BMI with gender, diet and life style.

\section{DISCUSSION}

There are very few studies which relate BMI with serum sodium and potassium and therefore this study was under taken to find out the correlation between BMI and serum electrolyte sodium and potassium in all the age groups.

Data analysis in one of the study indicated that serum $\mathrm{Na}^{+}$level was positively related to BMI and to systolic and diastolic BP in pre-HTN group (Syed and Qureshi, 2012) while our study partially contradicts with above study in relation to $\mathrm{Na}^{+}$ with BMI where it shows a more negative correlation of serum $\mathrm{Na}^{+}$and $\mathrm{K}^{+}$with BMI. With reference to Syed and Qureshi, 2012, in our study, the serum $\mathrm{Na}^{+}$is shown to be more positively related to SBP in addition to that we found the serum $\mathrm{K}^{+}$to be negatively related to SBP.

The obesity has many adverse effects on haemodynamics thus explaining the relation of increase in BMI with increase in blood pressure. One of the study states that excessive adipose accumulation leads to increased circulating blood volume which results in higher cardiac output caused by stroke volume in obese patients but a lower level of total peripheral resistance at any given level of arterial pressure (Alpert, 2002), although, heart rate is typically mildly increased because of increased sympathetic activation (Messerli et al., 1987). The above study support our finding of negative correlation of BMI with serum Sodium and Potassium which could be due to haemodilution resulting from increased blood volume in high BMI or obesity.

Our study showed that BMI is positively related to SBP and DBP which was found statistically significant $(\mathrm{p}<0.05)$. In another study which added further evidences for the direct relationship between blood pressures and BMI, blood pressures and age, as well as blood pressures and sodium concentrations (Lufti, 2012). As per INTERSALT study, the correlation coefficient was higher when correlating BMI with blood pressure thus pointing to the risk of developing hypertension in those having high BMI (Dyer, 1990).

It can be stated that the an increase in blood volume in high BMI (overweight and obese) can be one of the factor in increasing the blood pressure and at the same time may be responsible for lowering serum $\mathrm{Na}+$ and $\mathrm{K}+$ levels due to haemodilution which correlates with the findings of our study. 


\section{CONCLUSION}

Our study concludes that BMI has an association with serum $\mathrm{Na}^{+}$and $\mathrm{K}^{+}$levels. BMI has a definite role in the development of hypertension. Awareness shoud be made about the BMI and its association with blood electrolyte levels in mediating cardiovascular complications. Moreover stress should be given to have BMI within the normal range and preventive measure should be advised especially the lifestyle changes to the community at large.

\section{ACKNOWLEDGEMENT}

We are grateful to the people of Srinagar, Garhwal for voluntarily participating and co-operation in the study without them this study would not have been possible.

Financial support and sponsorship: Our sincere thanks to the Principal, VCSGGMS \& RI, Srinagar, Uttarakhand and the medical superintendant of HNB Base Hospital, Srikot, Srinagar who supported the ICMR STS Project 2014 and gave permission to conduct the study.

Conflict of Interests: There are no conflicts of interest.

\section{REFERENCES}

Alpert MA. Obesity cardiomyopathy: pathophysiology and evolution of the clinical syndrome. Am J Med Sci 2001;321(4):225-36.

Bogers RP, Bemelmans WJ, Hoogenveen RT, Boshuizen HC, Woodward M, Knekt P, van Dam RM, Hu FB, Visscher TL, Menotti A, Thorpe RJ Jr, Jamrozik K, Calling S, Strand BH, Shipley MJ; BMICHD Collaboration Investigators. Association of overweight with increased risk of coronary heart disease partly independent of blood pressure and cholesterol level; a meta-analysis of 21 cohort studies including more than 300000 persons. Arch Intern Med 2007; 167(16): 1720-1728.

Burgess E, Lewanczuk R, Bolli P, Chockalingam A, Cutler H, Taylor G, Hamet P. Lifestyle modifications to prevent and control hypertension.6. Recommendations on potassium, magnesium and calcium. Canadian hypertension Society. Canadian Coalition for High Blood Pressure Prevention and Control, Laboratory Centre for Disease Control at Health Canada, Heart and Stroke Foundation of Canada. Can Med Assoc J 1999;160(9 suppl) : S35-S43.

Cooper R, Van Horn L, Liu K, Trevisan M, Nanas S, Yu CS, Sampos C, Stamler J. A randomized trial on the effect of decreased dietary sodium intake on blood pressure in adolescents. J hypertans, 1984; 2: 361366.

Dahil LK, Silver L, Christie RW. The role of salt in the fall of BP accompanying reduction in obesity. N Engl J Med. 1958; 258 : 11861192.

Dores H, Santos P, Salvador F, Maia J, Paixāo L, Pereira R, Gonçalves N, Leitāo A, Fonseca C, Ceia F. Blood pressure in young adults. Rev Port Cardiol. 2010; 29(10): 1495-508.
Dudekula AB, Naik JL, Reddy KSN. Correlation between blood sugars and BMI with blood pressure among the type 2 diabetic adults. Asian J Exp Biol Sci. 2012;3(2):378-383.

Dyer AR, Elliott P, Shipley M. BMI versus height and weight in relation to blood pressure. Findings for the 10,079 persons in the INTERSALT study. Am J Epidemiol. 1990;131:589-96.

Falkner B, Gidding SS, Ramirez-Garnica G, Wiltrout SA, West D, Rappaport EB. The relationship of BMI and blood pressure in primary care pediatric patients. J Pediatr. 2006;148:195-200.

Gundogdu Z. Relationship between BMI and blood pressure in girls and boys. Public Health Nutrition: 2008;11, 1085-1088.

He FJ, Mac Gregor GA, Effect of modest salt reduction on BP. J Hum Hypertension. 2002; 16:761-773.

Heyden S, Tyroler KA, Hames CG, Bartel A, Thompson JW, Krishan I, Rosenthal T. Diet treatment of obese hypertensives. Clin Sci Mol Med 1972; 45 : 209-212.

Jankunas, R, Volbekas, V, Stakisaitis, D, and Driziene, Z. Urinary sodium: Gender related differences and relation to blood pressure in adolescents. Acta medica Lituanica.2002; 2: 86-92.

Lutfi MF. Effects of age, BMI and electrolytes levels on blood pressures of normotensive adults. Khartoum Medical Journal. 2012; 05(1): $673-681$.

MacMahon S, Peto R, Cutler J, Collins R, Sorlie P, Neaton J, Abbott R, Godwin J, Dyer A, Stamler J. Blood pressure, stroke, and coronary heart disease. Part 1, Prolonged differences in blood pressure: prospective observational studies corrected for the regression dilution bias.Lancet 1990;335(8692):765-774.

Messerli FH, Nunez BD, Ventura HO, Synder DW. Overweight and sudden death: increased ventricular ectopy in cardiomyopathy of obesity Arch Intern ed 1987;147(10):1725-28.

Patil SP, Sukumaran S, Bhate A, Mukherjee A, Chandrakar S. Correlation of blood sugar with waist circumference and BMI in an Indian population. Global Journal of Pharmacology. 2012; 6(1):8-11.

Prineas RJ. Clinica interaction of salt and weight change on blood pressure level, Hypertension 1991; 17(Supple I): I 143- I 149.

Saely CH, Risch L, Frey F, Lupi GA, Leuppi JD, Drexel $\mathrm{H}$, Huber AR. Body mass index, blood pressure, and serum cholesterol in young Swiss men: an analysis on 56784 army conscripts. Swiss Med Wkly. 2009;139(35-36):518-24.

Smulyan H, Csermely TJ, Mukherjee S, Warner RA. Effect of age on arterial distensibility in asymptomatic humans. Arteriosclerosis. 1983;3:199-205.

Syed SB and Qureshi MA. Association of Aldosterone and Cortisol with Cardiovascular Risk Factors in Prehypertension Stage. International Journal of Hypertension. Volume 2012, Article ID 906327, 8 pages.

Warren V, Aberg H. Blood pressure in 60 year old men. Acta Med Scan 1979;266:99.

How to cite this article:

Pandey V, Dutt HK, Singh G, Vinod AP. Correlation of blood $\mathrm{Na}^{+}$ and $\mathrm{K}^{+}$levels with Body Mass Index in population of Garhwal region of Uttarakhand. J App Pharm Sci, 2017; 7 (01): 189-192. 